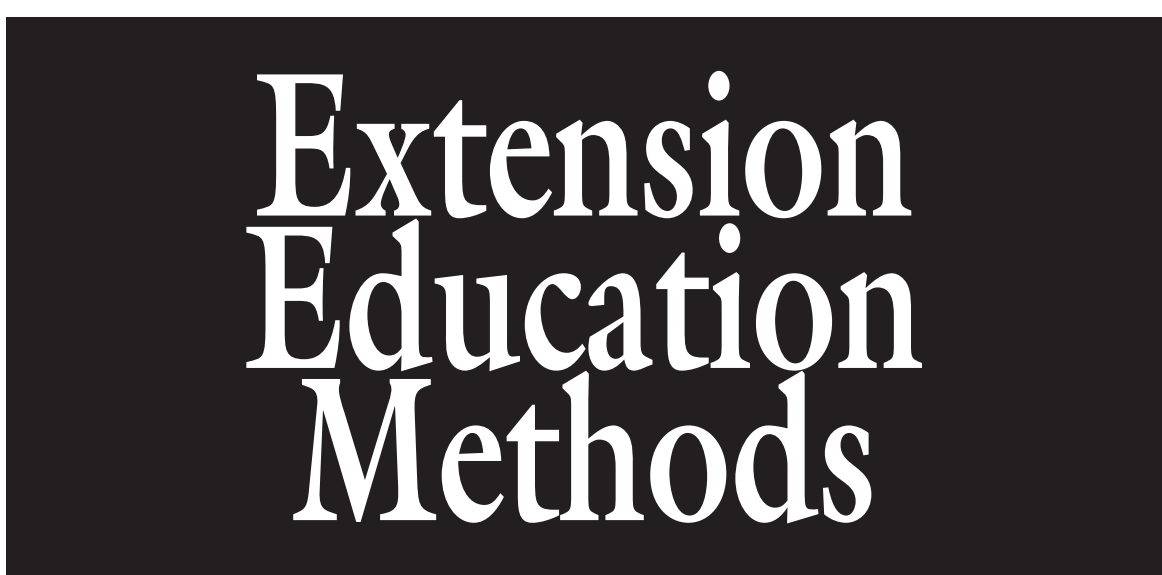

\title{
Results from Survey Instruments Used to Assess Technology Adoption for Tree Fruit Production
}

\author{
Katie Ellis ${ }^{1,3}$, Tara Auxt Baugher ${ }^{1}$, and Karen Lewis ${ }^{2}$
}

ADDITIONAL INDEX WORDs. socioeconomic survey, automation, harvest assist

Summary. Advances in horticultural production technology are often hindered by slow grower adoption. Low adoption rates are largely the product of skepticism, which can lead to weaknesses in the commercialization process and affect future research and product development. To better understand industry concerns and design effective outreach methods, an information technology survey was designed as part of the U.S. Department of Agriculture Specialty Crop Research Initiative project titled Comprehensive Automation for Specialty Crops (CASC). This study outlines the survey results from 111 participants at tree fruit meetings in the Pacific northwestern and eastern United States in 2009. Many of the misgivings about new automated technologies, such as equipment cost and reliability of harvest assist, sensor systems, and fully automated harvest machinery, were consistent across the country. Subtle differences appeared between the eastern U.S. and Pacific northwestern U.S. responses, including justifiable equipment price points and irrigation and pest concerns; these are likely attributable to regional differences in climate, operation size and scale, and marketing strategies. These survey data will help the project team better address grower concerns and uncertainty on a regional and national level, thereby improving adoption speed and rates after CASC-developed technologies are rolled out.

\section{A} lthough automated and precision agriculture initially took off in agronomic crops, it has remarkable value for horticultural specialty crops such as tree fruit (Roberson, 2000 ). High crop value per unit area and crop response to environmental variables make advanced production technology an important prospect. However, agricultural technology often outpaces the readiness of growers. Modern farming is already complex; producers want to try new science and technologies, but they also value simplicity (Kitchen, 2008).

A number of factors can hamper adoption, including overly complex systems, cost, risk aversion, and perceived negative return on investment (Adrian et al., 2005; Koundouri et al., 2006; Reichardt and Jürgens, 2009; Sassenrath et al., 2008). Other factors that work to enhance adoption rates are the following: perceived economic benefits, ease of use, simplicity, and the potential of technology to decrease production risks (Adrian et al., 2005; Sassenrath et al., 2008). Higher education levels are also generally associated with early adoption, though widespread computer use may be diminishing this effect (Adrian et al., 2005).

Llewellyn (2007) reports that the variation in time to adoption is often attributed to differences in knowledge and perception about the relevant advantage of a technology. To reduce the overall time to adoption, it would be useful to identify early adopters (typically 13\% of a given grower group). Early adopters are often highly educated or fill a local leadership role; their endorsement can carry weight among the early majority (34\%) and late majority $(34 \%)$ adopters who tend to hedge their bets by obtaining information from them (Lamb et al., 2008). Those who have the least uncertainty about technology, the lowest evaluation costs, and larger farms tend to adopt new equipments and ideas earlier than others (Barrett et al., 2010).

Earlier research shows that it takes roughly 8 years from the time of public research dollar investment to the implementation of technology by early adopters. In the agricultural sector, it can take as long as 15 years before full adoption by stakeholders occurs (Alston et al., 1995). In the realm of automation and precision agriculture, many technologies become obsolete in 15 years, creating a need to increase the speed of adoption.

This is particularly important for successful rollout of new equipment developed as part of recent horticultural technology initiatives. The CASC project is a Specialty Crop Research Initiative program funded through the National Institute of Food and Agriculture, U.S. Department of Agriculture. CASC goals include the development of information technologies that enhance tree fruit crop monitoring, reduce labor, and increase fruit quality and yields. The project also aims to accelerate technology adoption by analyzing its return on investment and identifying and mitigating barriers to adoption.

A CASC socioeconomic survey was drafted in Jan. 2009 to solicit stakeholder input and identify potential obstacles to industry adoption of new automation technologies developed for tree fruit production. The survey tool had 35 questions and a brief explanation of the project and the purpose of the survey. The questions were grouped into seven related sections specific to technologies under development by CASC project leaders: 1) demographic information and farm enterprise specifics; 2 ) needs/potentials for automation and sensor technologies in specialty crops; 3) potential benefits of harvestassist (semiautomated harvest) technology; 4) potential benefits of automated 
disease detection and pest monitoring technologies; 5) potential benefits of automated technologies for monitoring plant stress; 6) benefits of fully automated harvest technologies; and 7) specific orchard system planting information.

We planned to identify key areas for outreach and education by surveying tree fruit growers about their operations, their opinions on fruit production technology, and their likelihood of adopting new equipment. Our goal is to use the survey data and participant comments to increase the rate and reduce the time to adoption of technologies developed as part of the CASC project. These data will help us identify and address specific misgivings about the ease of use, reliability, and return on investment of new equipment. We also hoped to identify regional topics of interest or concern to tree fruit producers in the eastern United States vs. the Pacific northwestern United States (Pacific Northwest) to develop audience-specific outreach materials and events.

\section{Materials and methods}

A paper survey was initially distributed to audience members at the Tree Fruit session held during the Feb. 2009 Mid-Atlantic Fruit and Vegetable Convention in Hershey, PA; participation was $87 \%$. Sample questions are shown in Fig. 1. Additional eastern growers were surveyed at the Feb. 2009 Empire State Fruit and Vegetable

This work was supported by the U.S. Department of Agriculture under the Specialty Crop Research Initiative, award number 2008-51180-04876, the State Horticultural Association of Pennsylvania, the Washington Tree Fruit Research Commission, and the Penn State College of Agriculture Seed Grant Program.

We acknowledge the valuable contributions of $\mathrm{N}$. Lehrer and D. Ames, Department of Sociology, Washington State University; J. Harper, Department of Economics and Rural Sociology, Penn State University; J. Chambers, Penn State Cooperative Extension; and the Comprehensive Automation for Specialty Crops project team leaders, S. Singh (Project Director), M. Bergerman (Project Manager), H. Ngugi, M. Glenn, and J. Park (Plant Stress and Disease Detection), L. Hull, V. Jones, and J. Park (Insect Monitoring), T. Koselka (Crop Load Scouting), J. Owen (Caliper Measurement), B. Grocholsky (Information Management), G. Kantor (Accurate Positioning), W. Messner (Augmented Harvesting), B. Hamner (Reconfigurable Mobility), C. Seavert (Value Proposition), and G. Hoheisel (Technology Adoption) for input on the survey questions.

${ }^{1}$ The Pennsylvania State University, 670 Old Harrisburg Road, Gettysburg, PA 17325

${ }^{2}$ Washington State University, P.O. Box 37, Ephrata, WA 98823

${ }^{3}$ Corresponding author. E-mail: kag298@psu.edu.

Please give us your insights on the needs and potentials for

automation/sensor technologies in specialty crops:

8. To improve precision and efficiency in your specialty crop enterprise, what are the areas of greatest need for advanced technologies such as those already applied to medicine, manufacturing, and other fields?

For each area, please check $a$ box ranging from $1=$ No need to $5=$ Significant need:

\begin{tabular}{r|r|r|r|r|r|}
\hline & No need & & & & $\begin{array}{c}\text { Significant } \\
\text { need }\end{array}$ \\
Fruit thinning & 1 & 2 & 3 & 4 & 5 \\
\hline Tree training & & & & & \\
\hline Pruning & & & & & \\
\hline Harvesting & & & & & \\
\hline Spraying & & & & & \\
\hline Mowing & & & & \\
\hline $\begin{array}{r}\text { Monitoring plant and soil water and } \\
\text { nutrient status }\end{array}$ & & & & \\
\hline quality assessments) & & & & & \\
\hline
\end{tabular}

Please give us your input on potential benefits of fully automated harvest technologies

29. One of the steps toward fully automated harvest will be the development of technologies for scouting crop load in an orchard block at various times of the season. What do you perceive as the major benefit(s) of imaging/information management systems that scout and map crop load?

Please check all that apply:

$\square$ More efficient management of fruit thinning

$\square$ Improved preparations for harvest and storage of fruit

$\square$ Accurate pre-harvest projections of crop volume and fruit size for improved marketing

$\square$ Improved management of orchard inputs, e.g., water, plant nutrients

$\square$ Other Please explain:

30. What do you perceive as the main obstacles to industry adoption of fully automated harvest?

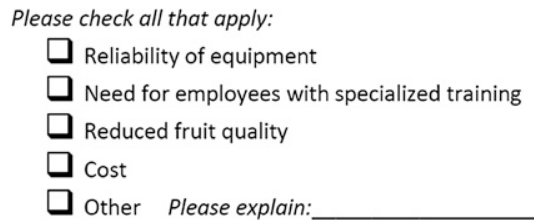

Fig. 1. Sample survey questions 8, 29, and 30 from the full survey distributed to tree fruit growers in Pennsylvania, New York, and Washington.

Expo in Syracuse, NY. A shorter instant response survey, TurningPoint ${ }^{\circledR}$ (Turning Technologies, Youngstown, $\mathrm{OH}$ ), was also conducted during automation presentations at both conventions. U.S. growers in the Pacific Northwest were asked to complete the survey at the Dec. 2009 Washington State Horticultural Association Convention held in Wenatchee, WA. Eastern U.S. survey response data and Pacific Northwest survey response data were summarized and compared, using median values for rated scale data.
An abridged form of the full paper survey was distributed to participants at the President's Day Fruit Growers Educational Meeting held in Biglerville, PA, in Feb. 2009. The shortened survey was more opinion based and did not include specific questions about the participant's orchard operation. About $40 \%$ (58) of participants responded. More employees and orchard managers (relative to owners) were represented in the Biglerville audience. All survey answers were anonymous, with no identifiers other than meeting location.

\begin{tabular}{llll}
\hline $\begin{array}{l}\text { Units } \\
\begin{array}{l}\text { To convert U.S. to SI, } \\
\text { multiply by }\end{array}\end{array}$ & U.S. unit & SI unit & $\begin{array}{l}\text { To convert SI to U.S., } \\
\text { multiply by }\end{array}$ \\
\hline 0.4047 & acre(s) & ha & 2.4711
\end{tabular}




\section{Results and discussion}

Of the full surveys completed, 65 were collected in Pennsylvania, 38 in Washington, and 8 in New York. The breakdown of roles from the full survey was as follows: 74 owner/principles, 19 managers, 7 employees, and 11 "other" participants. Growers of 11 different tree fruit and vine crops were represented, with a total of 17,279 acres managed. Nearly all growers managed at least $\mathrm{l}$ acre of apples (Malus spp.). Fresh apple acreage dominated the totals, followed by processing apples, pears (Pyrus spp.), and peaches and nectarines (Prunus persica). Most operations grew fairly diverse arrays of tree fruit crops, with half of all eastern growers producing five or more different crops. Pacific Northwest growers reported less diversity in crop makeup, but tended to manage more acreage.

The annual gross revenue of each participant's operation was almost equally distributed across the following categories: $<\$ 250,000(22 \%), \$ 250,000$ to $\$ 500,000(23 \%), \$ 500,000$ to $\$ 1$ million $(21 \%)$, and $\$ 1$ million to $\$ 5$ million (27\%). Respondents with annual gross revenues more than $\$ 5$ million were in the minority $(7 \%)$; all but one in this category were from the Pacific Northwest. In the eastern United States, retail marketing (67\%) was the most commonly used marketing technique, followed by shippers/ packers $(45 \%)$, farmers' markets (43\%), and processors (37\%). Shipping/packing was much more common in the Pacific Northwest (90\%).

Besides farm enterprise information, respondents were asked to give their opinions about the needs and potentials for automation and sensor technologies in specialty crops. To improve precision and efficiency in orchard enterprises, the participants rated fruit thinning, harvesting, spraying, and monitoring crop and nutrient status as the greatest areas of need. Among these, thinning and harvesting tended to receive the highest need scores (Fig. 2). Advanced technologies in tree training and mowing were seen to be least important, especially in the Pacific Northwest. Advanced technologies in pruning were rated as more important by eastern U.S. growers.
With regard to harvest-assist technologies, most participants anticipated benefits through increased workforce productivity and improved management of harvest operations. Eastern growers anticipated reduced costs with new technologies more than Pacific northwestern growers, who saw more benefits with the reduced need for a steady workforce. When asked, respondents identified cost and fruit damage as being major obstacles to the adoption of harvest-assist technologies. Growers in the Pacific Northwest also had major concerns about equipment reliability. In contrast, decreased employee retention, decreased safety, reduced control over management of harvest operations, and the need for specialized employee training were not seen as major obstacles. Participants suggested on-farm trials and field demonstrations as educational opportunities to speed adoption. As in the harvestassist responses, the major obstacles to overcome adoption of fully automated harvest technologies are cost, equipment reliability, and reduced fruit quality (Fig. 3). Comments indicated that growers were more likely to accept
A

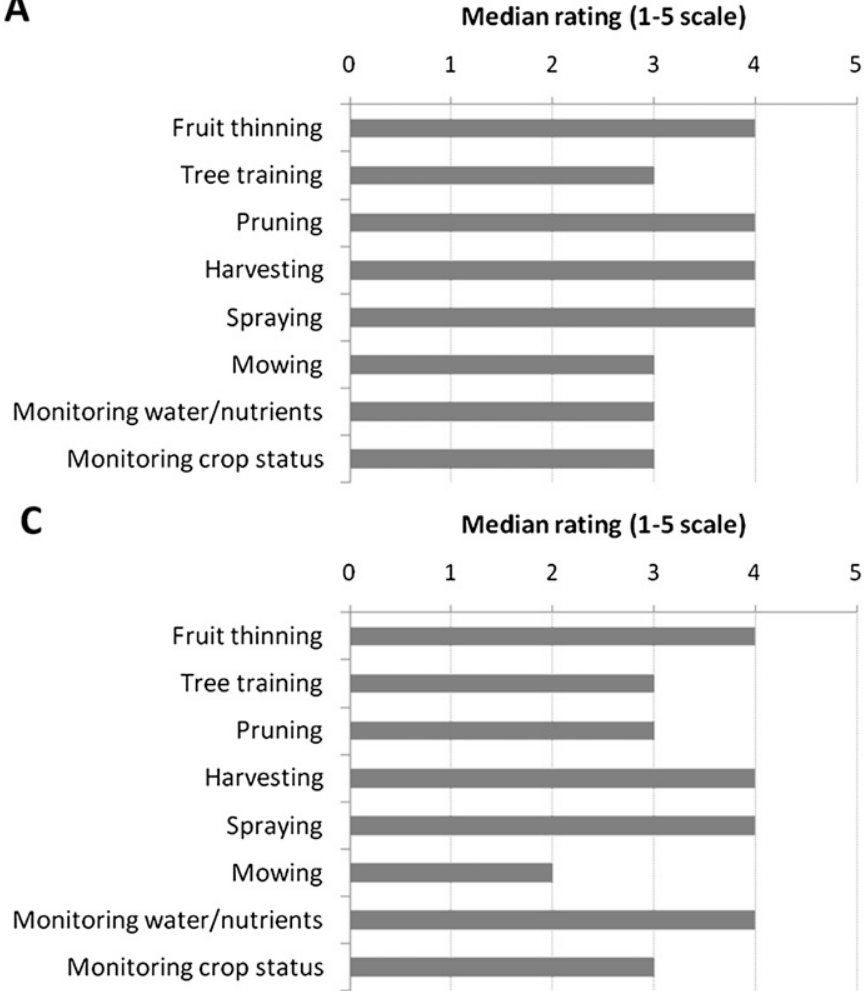

B

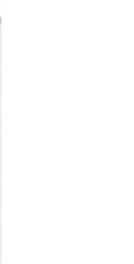

Monitoring water/nutrients Monitoring crop status

\section{Median rating (1-5 scale)}

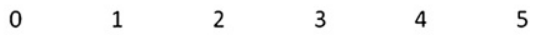

Fig. 2. Median rating of areas of need for advanced technologies to improve precision and efficiency in tree fruit production ( $1=$ no need, $\mathbf{5}$ = significant need). Responses are separated by meeting locations/audience: (A) eastern United States (Hershey, PA/Ithaca, NY), (B) Pacific northwestern United States (Wenatchee, WA), and (C) Biglerville, PA (shortened survey with higher employee:owner ratio). 
A

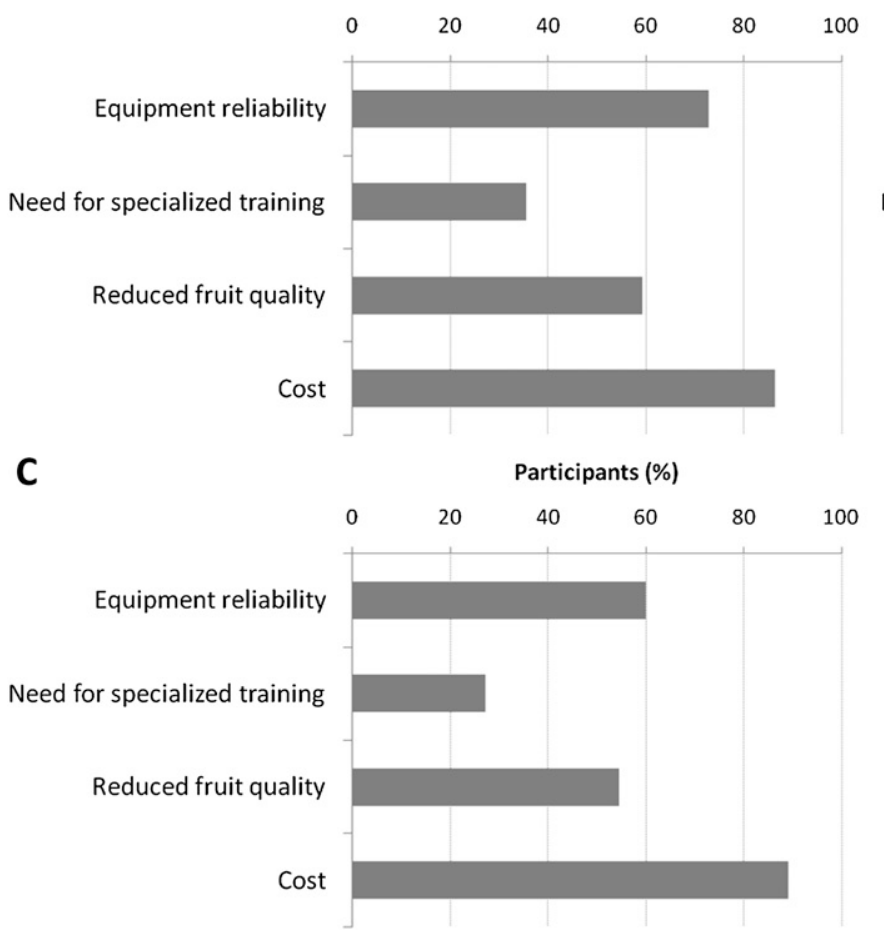

B

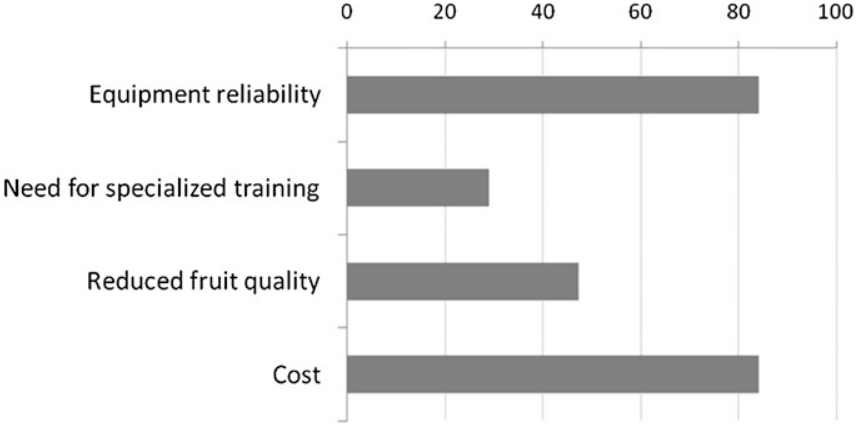

Fig. 3. Percentage of participants who identified potential hindrances to adoption of fully automated harvest of tree fruit. Responses are separated by meeting locations/audience: (A) eastern United States, (B) Pacific northwestern United States, and (C) Biglerville, PA (shortened survey with higher employee:owner ratio).

equipment that incorporated humanlike movements and field-demonstrated capabilities.

Participants were also asked to identify the maximum equipment price justified by an increase in efficiency of harvest employees by $30 \%$ to $40 \%$. The median price justified by each regional group was $\$ 35,000$. If harvest technologies increased fruit packout by $10 \%$ to $15 \%$, eastern U.S. respondents felt $\$ 25,000$ was reasonable; however, Pacific Northwest growers justified a much higher price point of $\$ 55,000$.

Fire blight (Erwinia amylovora) infection seemed to be an important concern for eastern U.S. fruit growers, though recent losses to the disease were moderate. Seventy percent of those surveyed in Pennsylvania and New York estimated their losses to fire blight as fewer than 100 trees within the last 5 years. When asked if a vision/decision support system for early detection and mapping of fire blight strikes would assist in improving the removal of blighted shoots to avoid tree loss, $79 \%$ agreed.

Imaging systems that detect the onset of water stress and provide an input to irrigation control systems were more important to Pacific Northwest
(92\%) than eastern U.S. growers (70\%). Participants in the Pacific Northwest were willing to incorporate sensor technologies into their irrigation systems as long as they achieved 35\% energy and/ or $50 \%$ water savings. In the eastern United States, willingness to redesign irrigation systems was fairly low, at a median response of $25 \%$ for each consideration.

Internal fruit-feeding insects, such as codling moth (Cydia pomonella) and oriental fruit moth (Grapholita molesta), were seen as a problem for $52 \%$ of eastern U.S. and $82 \%$ of Pacific Northwest participants. Most respondents were optimistic about automated pheromone traps that could identify and $\log$ codling moth and oriental fruit moth activity. In both regions, most respondents also indicated that they would, at minimum, use the same number of new traps if reliable imaging traps were available. Many wrote that they would increase the number of traps used, up to 75 additional traps per pest per operation. Survey results also suggest that growers will consider increasing trap density with new technologies (within the current area under a monitoring regime) but will not expand their program to larger areas.
Of the four potential obstacles posed by the survey to industry adoption of new sensor technology for insect monitoring (reliability of equipment under varying conditions, complexity, need for specialized training, and cost), most felt that cost and equipment reliability under varying environmental conditions were most prohibitive. However, the research and outreach efforts suggested to speed adoption were regarded as potentially useful, especially on-farm trials demonstrating pest management benefits (Fig. 4).

Efficient and effective fruit thinning were seen as the most beneficial results from imaging systems that can scout and map crop load. The majority of those surveyed also felt that preharvest projections of crop load/fruit size and improved management of crop inputs were benefits of the move toward fully automated harvest. Pacific Northwest participants were particularly interested in preharvest projections of crop volume and fruit size for improved marketing.

In general, the results from both the full survey designed for orchard owners and the abridged survey designed for orchard employees and 
A

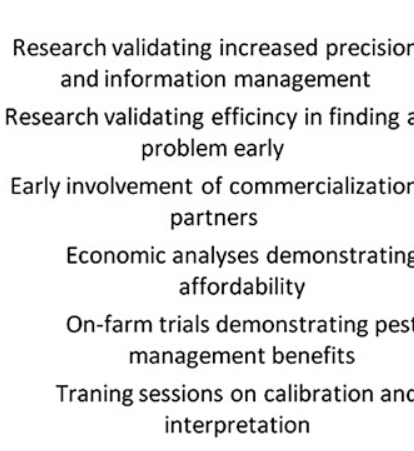

C

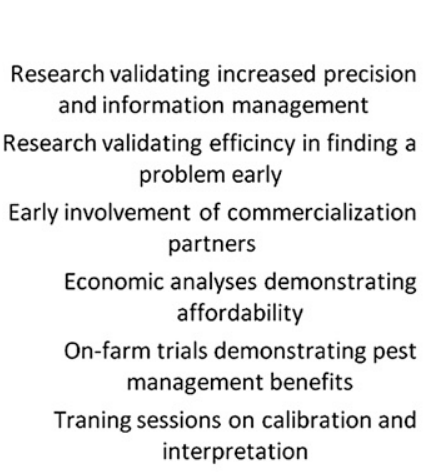

Respondents (\%)

$\begin{array}{llllllllll}0 & 10 & 20 & 30 & 40 & 50 & 60 & 70 & 80 & 90\end{array}$

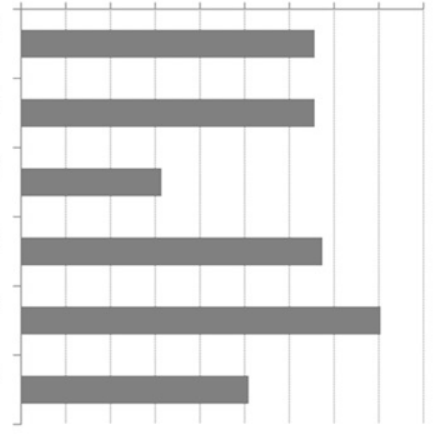

Respondents (\%)
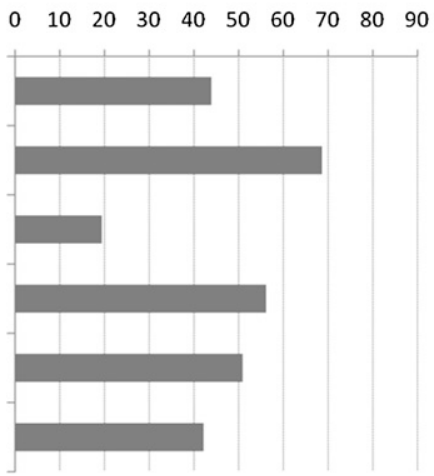

B

Respondents (\%)

$\begin{array}{llllllllll}10 & 20 & 30 & 40 & 50 & 60 & 70 & 80 & 90\end{array}$

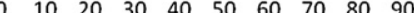

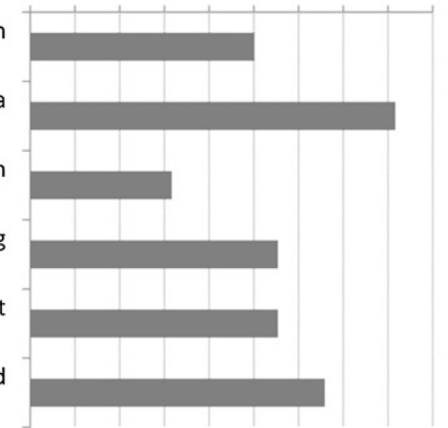

Fig. 4. Percentage of respondents who were more likely to adopt precision systems for detecting disease and monitoring insects in tree fruit due to various research and outreach efforts/audience. Responses are separated by meeting locations: (A) eastern United States, (B) Pacific northwestern United States, and (C) Biglerville, PA (shortened survey with higher employee:owner ratio).

managers were very similar. Abridged survey results showed that equipment affordability was seen to be the primary concern for developments in orchard technology. Efficiency in fruit thinning, crop load scouting, and disease/insect spot treatments were seen as the greatest benefits from new developments. Participants in the short survey saw more benefits to automation in sprayer technologies than the group that took the full one; they were also generally less concerned with equipment reliability and ease of repair. Employees seemed confident in their abilities to use, interpret, and repair new systems, whereas owners saw more benefit in on-farm trials and training sessions.

\section{Implications for improvements in technology adoption}

Orchard owners and managers identified fuel costs, labor regulations, labor costs, insurance costs, and market conditions as the most important external influences on their businesses. Water availability/cost and quarantine regulations were least important. Therefore, upcoming research and outreach objectives should emphasize economic analyses that present evidence of increased returns and workforce productivity. If water availability was addressed, its impact would be more keenly felt by growers in the Pacific Northwest, an area under the prior appropriation doctrine of water law. Eastern U.S. growers, who follow the riparian doctrine, are less affected by water law restrictions.

Climate and water availability may have contributed to the disparity between eastern U.S. and Pacific Northwest growers' area of need scores for technology applications in pruning and mowing (Fig. 2). Restricted water availability limits tree vigor to a greater extent in the Pacific Northwest than in the eastern United States. Water also impacts required mowing frequency, which tends to be greater for eastern U.S. growers.

Llewellyn (2007) suggests a broad approach to target research and extension efforts to influence adoption decisions. A range of factors can influence technology adoption, which is seen in these data; although growers have strong opinions about emerging technologies, it is difficult to parse the responses into single factors that will sway producers to try new equipment.

Most stakeholders acknowledge a wide range of benefits from orchard automation technologies. To speed industry adoption, growers need to be assured of equipment reliability and safety. Harvest operations are time sensitive, and so harvest-assist or fully automated harvest equipment malfunction could have serious consequences on production and profits. Growers can be assured of equipment reliability through extensive research and development, high-quality equipment manufacturing, and local, vested dealers. Equipment and employee safety can be addressed in equipment design, on-farm training, and regulatory oversight. Employee retention can be addressed on an individual farm basis, and harvest control concerns probably do not need to be addressed in detail.

Although internal fruit feeder pressure appears low in some areas, 
growers seem eager to adopt automated insect-trapping systems soon; this should be a great thrust area. Nearly 100\% of respondents who regularly trap fruit-feeding moths were willing to adopt the same number of automated traps (or more). If automated traps are reliable and affordable, they could be one of the first CASCdeveloped technologies to be adopted by growers.

Although most responses were consistent across the country, Pacific Northwest and eastern U.S. growers indicated differences in irrigation concerns and justifiable price points for harvest-assist technology. This result suggests a benefit in using regionspecific outreach topics to emphasize local needs for some topics. Pacific Northwest growers with larger packand-ship operations associate a benefit with packout improvement, whereas smaller eastern U.S. retail-based businesses would relate better to emphasis on reduced labor costs and enhanced fruit quality.

Growers in the Pacific Northwest were also particularly interested in sensor data for crop projections, which may be due in part to recent disparities between projected and actual crops. Several months before the Pacific Northwest survey, Washington growers were faced with a large crop of unusually small apples. In addition, the 2008 actual fresh crop was nearly $11 \%$ more than the total projected that summer (Yakima Valley Growers-Shippers Assn., unpublished data). Therefore, recent reminders of crop variability may influence the participants' opinions and interest in specific sensor technologies.

Growers place a high value on "in my backyard" field trials and are more likely to adopt innovations that are developed or tested locally (Llewellyn, 2007). Comments from this survey confirm that tree fruit growers want to see technological benefits through on-farm trials, particularly in the eastern United States. Case studies of growers who borrowed machinery are generally positive and can help prioritize needs in overcoming adoption problems (Baugher et al., 2010; Llewellyn, 2007). Growers who use the equipment may also serve as reliable sources of first-hand knowledge, which will quickly diffuse information among members of local grower groups (Lamb et al., 2008). CASC uses demonstration field days and on-farm pilot studies to encourage users to try out new equipment. Grower cooperators have willingly offered feedback about their experiences and suggestions to improve user interfaces and equipment design. Lamb et al. (2008) suggest that a technology's reputation is most vulnerable in the earliest stages of adoption. Therefore, adequate field testing is critical for allaying grower skepticism in the early adopter segment and helping speed the time to adoption.

CASC members designed this project to bridge the gap between developer and end user, welcoming grower input and addressing factors that may influence adoption rates. The project incorporates an advisory panel of industry stakeholders and private orchard managers to offer continued feedback. A website offers up-to-date information about project progress and educational outreach materials, and training is offered for related value proposition tools. Through suggestions from stakeholders, project area leaders have also incorporated plans that improve fruit quality, such as bin fillers and harvest-assist machine designs that reduce fruit bruising. As CASC continues, further case studies will reveal if grower feedback and the project's subsequent evolution truly worked to change adoption rates.

\section{Literature cited}

Adrian, A.M., S.H. Norwood, and P.L. Mask. 2005. Producers' perceptions and attitudes toward precision agriculture technologies. Comput. Electron. Agr. 48: 256-271.

Alston, J.M., G.W. Norton, and P.G. Pardey. 1995. Science under scarcity:
Principles and practice for agricultural research evaluation and priority setting. Cornell University Press, Ithaca, N.Y.

Barrett, C.B., M.R. Carter, and C.P. Timmer. 2010. A century-long perspective on agricultural development. Amer. J. Agr. Econ. 92:447-468.

Baugher, T.A., J. Schupp, K. Ellis, J. Remcheck, E. Winzeler, R. Duncan, S. Johnson, K. Lewis, G. Reighard, G. Henderson, M. Norton, A. Dhaddey, and P. Heinemann. 2010. String blossom thinner designed for variable tree forms increases crop load management efficiency in trials in four United States peach-growing regions. HortTechnology 20:409-414.

Kitchen, N.R. 2008. Emerging technologies for real-time and integrated agriculture decisions. Comput. Electron. Agr. 61: $1-3$.

Koundouri, P., C. Nauges, and V. Tzouvelekas. 2006. Technology adoption under production uncertainty: Theory and application to irrigation technology. Amer. J. Agr. Econ. 88:657-670.

Lamb, D.W., P. Frazier, and P. Adams. 2008. Improving pathways to adoption: Putting the right P's in precision agriculture. Comput. Electron. Agr. 61:4-9.

Llewellyn, R.S. 2007. Information quality and effectiveness for more rapid adoption decisions by farmers. Field Crops Res. 104:148-156.

Reichardt, M. and C. Jürgens. 2009. Adoption and future perspective of precision farming in Germany: Results of several surveys among different agricultural target groups. Precision. Agr. 10: 73-94.

Roberson, G.T. 2000. Precision agriculture technology for horticultural crop production. HortTechnology 10:448451 .

Sassenrath, G.F., P. Heilman, E. Luschei, G.L. Bennett, G. Fitzgerald, P. Klesius, W. Tracy, J.R. Williford, and P.V. Zimba. 2008. Technology, complexity and change in agricultural production systems. Renewable Agr. Food Systems 23: 285-295. 